\title{
O gênero Bulbophyllum (Orchidaceae) na Região Sul do Brasil
}

\author{
The genus Bulbophyllum (Orchidaceae) in southern Brazil
}

\author{
Werner Siebje Mancinelli ${ }^{1,2,3}$ \& Eric de Camargo Smidt ${ }^{1}$
}

\begin{abstract}
Resumo
Bulbophyllum Thouars possui distribuição pantropical, somando 1.200 espécies. Na região neotropical ocorrem ca. 70 espécies, a maioria no Brasil. A meta do trabalho foi realizar o estudo taxonômico de Bulbophyllum no sul do Brasil. Para isso realizou-se descrições, ilustrações, coletas e análise de exsicatas. No total foram encontradas 16 espécies, Bulbophyllum atropurpureum, B. chloroglossum, B. dusenii, B. epiphytum, B. gladiatum, B. glutinosum, B. granulosum, B. malachadenia, B. mentosum, B. meridense, B. micranthum, B. napelli, B. peri, B. plumosum, B. regnellii, B. tripetalum e um novo híbrido natural aqui descrito. Áreas de maior diversidade constituem-se no Cerrado da Escarpa Devoniana ena Mata Atlântica dos Vales do Ribeira e do Itajaí. Um novo sinônimo é proposto, sendo B. dacruzii sinonimizado sob B. peri. Palavras-chave: Cerrado, Dendrobiinae, híbrido novo, Mata Atlântica, taxonomia.
\end{abstract}

\begin{abstract}
Bulbophyllum Thouars has 1,200 species with pantropical distribution. In the Neotropical region occurring ca. 70 species, mostly in Brazil. The aim was the taxonomic study of Bulbophyllum in southern Brazil. The analysis of herbarium specimens, field collections, descriptions and illustrations were made for this study. In total 16 species from four Neotropical sections were found: Bulbophyllum atropurpureum, B. chloroglossum, B. dusenii, B. epiphytum, B. gladiatum, B. glutinosum, B. granulosum, B. malachadenia, B. mentosum, B. meridense, B. micranthum, $B$. napelli, B. peri, B. plumosum, B. regnellii, B. tripetalum and a new natural hybrid, described here. Areas of highest diversity are in the "Escarpa Devoniana" of Cerrado and Atlantic Forest in the Ribeira and Itajaí Valleys. A new synonym is proposed, $B$. dacruzii synonymized under $B$. peri.
\end{abstract}

Key words: Cerrado, Dendrobiinae, new hybrid, Atlantic Forest, taxonomy.

\section{Introdução}

Orchidaceae representa uma das maiores famílias dentre as Angiospermas, com 24.500 espécies e distribuição cosmopolita (Dressler 2005). A família possui cinco subfamílias: Apostasioideae, Vanilloideae, Cypripedioideae, Orchidoideae e Epidendroideae (Chase et al. 2003). Epidendroideae possui aproximadamente 18.000 espécies em 650 gêneros, com distribuição cosmopolita (Stevens 2001; Pridgeon et al. 2005).

Um dos maiores gêneros da subfamília, Bulbophyllum Thouars, possui ca. 1.200 espécies (Vermeulen 1987). O gênero apresenta distribuição pantropical de forma não homogênea (Smidt et al. 2007). Na região Neotropical ocorrem ca. 70 espécies, sendo 48 no Brasil, constituindo o Cerrado e a Mata Atlântica os biomas com maior diversidade para o gênero (Smidt et al. 2007; Barros et al. 2010).

O objetivo desta análise foi realizar o estudo taxonômico de Bulbophyllum para os estados da Região Sul do Brasil, apresentando chave de identificação, descrições, ilustrações e comentários para as espécies.

\section{Material e Métodos}

A Região Sul do Brasil possui uma área de $577.723 \mathrm{~km}^{2}$, composta pelos estados do Paraná, Santa Catarina e Rio Grande do Sul (Fortes 1979). Os tipos de vegetação ocorrentes nessa Região são a Estepe, Floresta Estacional Decidual, Floresta Estacional Semidecidual, Floresta Ombrófila Densa, Floresta Ombrófila Mista, Savana (Cerrado) e Savana Estépica (IBGE 2004).

Foram analisadas exsicatas dos herbários FLOR, FURB, HB, HBR, HCF, HUCP, HUEFS, HUEL, HUEPG, ICN, JOI, M, MBM, PACA, RB, SP e UPCB (acrônimos segundo Thiers 2011). O material coletado durante as saídas de campo seguiu procedimento de herborização de Fidalgo \& Bononi (1989) e posteriormente foi

\footnotetext{
${ }^{1}$ Universidade Federal do Paraná, Setor de Ciências Biológicas, Centro Politécnico, Jardim da Américas, Curitiba - PR, 81531-980. C.P. 19031.

${ }^{2}$ Autor para correspondência: werner.mancinelli@gmail.com
} 
depositado no herbário UPCB da Universidade Federal do Paraná.

A partir dos dados morfológicos e quantitativos obtidos, descrições foram elaboradas no software DeltaAccess v 1.9 (Hagedorn 2010) seguindo a terminologia usual do gênero (Vermeulen 1987; Smidt 2007) e utilizando caracteres encontrados nas espécies da Região Sul. Os dados de distribuição geográfica das espécies foram obtidos em Pabst \& Dungs (1975), Smidt (2007) e Barros et al. (2010). Foi indicado o período de floração de cada espécie tendo como base as exsicatas analisadas e dados complementares de Smidt (2007).

\section{Resultados e Discussão}

Para a Região Sul do Brasil, foram analisadas 230 exsicatas, referentes às coletas realizadas em 77 municípios dos três estados, sendo encontradas 16 espécies e um novo híbrido natural. O estado do Paraná possui 14 espécies e um híbrido natural, Santa Catarina oito espécies e Rio Grande do Sul que representa o limite austral do gênero na região neotropical (Smidt et al. 2007) possui duas espécies. Tanto no Cerrado como na Floresta Ombrófila Densa são encontradas oito espécies em cada, destacando-se o Cerrado ao longo da Escarpa Devoniana e a Floresta Ombrófila Densa dos Vales do Ribeira e do Itajaí. Na Floresta Ombrófila Mista e Floresta Estacional Semidecidual ocorrem duas espécies em cada.

Bulbophyllum Thouars, Orch. Iles Austr. Afr. Tab. Esp. 3 et Ic. T. 93-97. 1822.

Pseudobulbo globoso a ovóide, unifoliado. Folha apical, conduplicada, plana ou cilíndrica, carnosa ou coriácea. Inflorescência racemosa, lateral, ereta a geniculada, partindo da base do pseudobulbo, com flores dísticas ou espiraladas. Sépalas livres ou as laterais conatas, naviculares ou planas; pétalas planas; labelo inteiro ou trilobado, apêndices basais ausentes ou presentes, calo ausente ou presente, quilha carnosa abaxial ausente ou presente. Coluna com estelídeos ultrapassando ou não a antera; dentes ausentes ou presentes; pé da coluna lobulado na base ou inteiro. Polínias desprovidas de viscídios e caudículos. Fruto capsular.

\section{Chave de identificação para as seções de Bulbophyllum ocorrentes no sul do Brasil}

1. Folha coriácea, flores em disposição dística na inflorescência, dentes da coluna presentes.

2. Sépalas planas, labelo inteiro, calo ausente 3. B. sect. Napelli

2'. Sépalas naviculares, labelo trilobado, calo presente.

3. Sépalas laterais livres, pé da coluna lobulado na base 1. B. sect. Didactyle

3'. Sépalas laterais conatas, pé da coluna inteiro 4. B. sect. Xiphizusa

1'. Folha carnosa, flores em disposição espiralada na inflorescência, dentes da coluna ausentes

2. B. sect. Micranthae

1. Bulbophyllum sect. Didactyle (Lindl.) Cogn., Fl. Bras. 3(5): 595. 1902.

Pseudobulbo ovóide. Folha plana, coriácea. Inflorescência delgada, flores dísticas, escapo cilíndrico, raque ereta a pêndula. Sépalas livres, naviculares; pétalas planas; labelo trilobado, apêndices basais ausentes, calo presente, quilha carnosa abaxial ausente. Coluna com estelídeos ultrapassando a antera; dentes presentes; pé da coluna lobulado na base.

\section{Chave de identificação para as espécies de Bulbophyllum sect. Didactyle ocorrentes no sul do Brasil}

1. Sépalas 5-6 mm compr., labelo aparentemente glabro, margem sinuada

1'. Sépalas maiores que $9 \mathrm{~mm}$ compr., labelo piloso, margem inteira.

2. Margem apical do labelo com tricomas nitidamente maiores que os da face, sépalas verdes, pétalas com margem pilosa 1.1. B. meridense

2'. Margem apical do labelo com tricomas nitidamente menores ou iguais que os da face, sépalas amarelas a purpúreas, pétalas com margem glabra.

3. Lobo mediano orbicular, ápice apresentando prega 1.4. B. ×guartelae

3'. Lobo mediano oblongo a oblongo-elíptico, ápice explanado 1.3. B. tripetalum 
1.1. Bulbophyllum meridense Rchb.f., Linnaea 22: 836. 1850.

Fig. 1a

Epífita. Rizoma 0,5-1,7 cm compr. Pseudobulbo 1,7-2 × 0,9-1,9 cm. Folha 7,2-11,3 × $1,9-3,5 \mathrm{~cm}$, elíptica a oblonga, ápice obtuso a agudo. Inflorescência 19-36 flores; escapo 20,3-38 cm compr.; raque 12,6-25,1 cm compr., ereta a pêndula. Sépalas verdes com pontuações purpúreas; sépala dorsal 8-10 × 3-4,5 mm, lanceolada, 3-nervada, margem glabra, ápice agudo; sépalas laterais 8-10,5 × 3-4 mm, lanceoladas, 3-nervadas, margem glabra, ápice agudo; pétalas 3-4 × 1-2 mm, linearlanceoladas, brancas com pontuações purpúreas, 1-nervadas, margem pilosa, ápice agudo; labelo 4,5$5 \times 2-4 \mathrm{~mm}$, lobo mediano orbicular, lobos laterais orbiculares, purpúreo, calo com sulco, margem inteira, pilosa, tricomas da margem apical maiores que os da face, ápice truncado, explanado, liso.

Material selecionado: SANTACATARINA: Bombinhas, 4.V.2010, fl., W.S. Mancinelli \& L. Ceolin 1217 (UPCB).

Bulbophyllum meridense ocorre no Peru, na Venezuela e no Brasil (BA, ES, MG, PE, SC). No sul do Brasil a espécie foi encontrada somente em Santa Catarina, na Floresta Ombrófila Densa, entre altitudes de 1 a $300 \mathrm{~m}$. Floresce entre os meses de abril e dezembro. Assemelha-se a B. peri Schltr. e $B$. tripetalum Lindl., porém os tricomas longos do labelo e ápice truncado do lobo mediano diferenciam esta espécie.

1.2. Bulbophyllum peri Schltr. Notizbl. Bot. Gart. Berlin-Dahlem 8: 123. 1922. Bulbophyllum dacruzii Campacci, Colet. Orquídeas Brasil 8: 262. 2010. Tipo: MINAS GERAIS: Joanésia, VII. 2008, fl., J.F. Cruz 42 (holótipo SP!), syn. nov.

Fig. 1b-d

Epífita ou rupícola. Rizoma 0,6-1,8 cm compr. Pseudobulbo 1,5-2,4 × 1-2 cm. Folha 5-6,8 × 1,4-2,3 $\mathrm{cm}$, oblonga, ápice agudo a obtuso. Inflorescência 16-27 flores; escapo 18,5-27,3 cm compr.; raque 7,4-15,2 cm compr., ereta a pêndula. Sépalas castanhas; sépala dorsal 5-6 × 2,5-3 mm, ovada, 3-nervada, margem glabra, ápice agudo; sépalas laterais 5-6×2,5-3 mm, ovadas, 3-nervadas, margem glabra, ápice agudo; pétalas $2,5-3 \times$ ca. $1 \mathrm{~mm}$, linear-lanceoladas, amarelas com listras transversais purpúreas, 1-nervadas, margem glabra, ápice agudo; labelo 3-3,5 × $2 \mathrm{~mm}$, lobo mediano orbicular, lobos laterais orbiculares, purpúreo com lobos amarelos, calo com sulco, margem sinuada, aparentemente glabra, ápice arredondado, explanado, liso.

Material selecionado: PARANÁ: Campo Mourão, 26.III.2007, fl., M.G. Caxambu 1431 (HCF).
Bulbophyllum peri é endêmica do Brasil (GO, MG, PR). Floresce entre os meses de fevereiro e abril. Encontrado no Paraná nos municípios com remanescentes de Cerrado. Espécie vegetativamente indistinguível de $B$. tripetalum, mas diferenciada pelas sépalas castanhas, labelo purpúreo com os lobos laterais amarelos e o lobo mediano orbicular, aparentemente glabro (pois apresenta pilosidade quase imperceptível ao microscópio esteoroscópico).

1.3. Bulbophyllum tripetalum Lindl., Ann. Mag. Nat. Hist. 10: 185. 1842.

Fig. 1e

Epífita ou rupícola. Rizoma 0,7-4,2 cm compr. Pseudobulbo 1,3-2,8 $\times 0,6-1,2 \mathrm{~cm}$. Folha $5,1-7,8 \times 1,3-2,4 \mathrm{~cm}$, oblonga, ápice agudo a obtuso. Inflorescência 9-17 flores; escapo 14,521,6 cm compr.; raque 9,8-14 cm compr., ereta. Sépalas amarelas; sépala dorsal 14-16 × 3,5-4,5 $\mathrm{mm}$, lanceolada, 3-nervada, margem glabra, ápice agudo; sépalas laterais $13,5-17 \times 3-4,5 \mathrm{~mm}$, lanceoladas, 3-nervadas, margem glabra, ápice agudo; pétalas 2,5-3,5 × 1-1,5 mm, ovadas, brancas com pontuações purpúreas, 1-nervadas, margem glabra, ápice agudo; labelo 6,5-7,5 × 2-3,5 mm, lobo mediano oblongo a oblongo-elíptico, lobos laterais orbiculares, amarelo com máculas vermelhas a pretas, calo com sulco, margem inteira, pilosa, ápice arredondado, explanado, liso.

Material selecionado: PARANÁ: Jaguariaíva, 17.IV.1911, fl., P. Dusén 11721 (MBM).

Bulbophyllum tripetalum ocorre no Paraguai e no Brasil (MG, MT, PR, RJ, SP). Floresce entre os meses de janeiro e agosto. Ocorre no Paraná em vegetação de Cerrado e comumente em Floresta Estacional Semidecidual. Espécie vegetativamente muito semelhante a $B$. meridense e $B$. peri, porém as flores de $B$. tripetalum são reconhecidas por sua coloração predominantemente amarela, lobo mediano oblongo a elíptico e maior tamanho das peças do perianto em relação às demais.

1.4. Bulbophyllum $\times$ guartelae Mancinelli \& E.C. Smidt, nothosp. nov. Tipo: PARANÁ: Tibagi, 15.III.2010, fl., W.S. Mancinelli \& D.L. Ferreira 1173 (UPCB). $\quad$ Fig. 2

Planta inter B. tripetalum Lindley et B. peri Schlechter intermedia et verisimiliter, aliis characteribus inter parentes media. Haec epiphytica, repens; pseudobulbis ovoideis, unifoliatis; folio oblongo, apice obtuso; inflorescentia basi, erecta, racemiflora; flore resupinate; sepalis lanceolatis, 


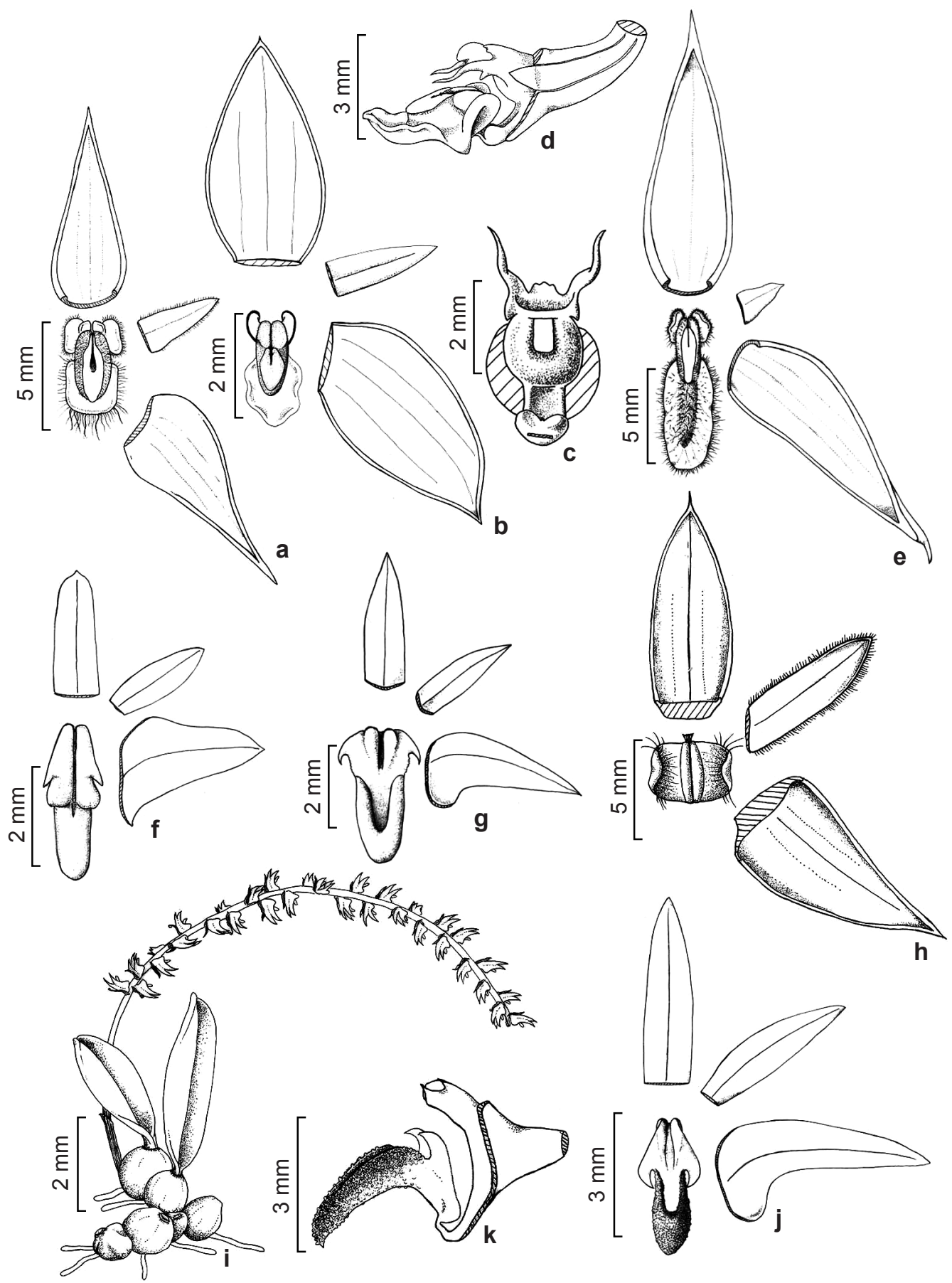

Figura 1 - a. Bulbophyllum meridense Rchb.f. - peças florais (W.S. Mancinelli \& L. Ceolin 1217). b-d. B. peri Schltr. - b. peças florais; c. coluna em vista frontal; d. coluna e labelo em vista lateral (W.S. Mancinelli \& M.E. Engels 1143). e. B. tripetalum Lindl. - peças florais (W.S. Mancinelli \& M.E. Engels 1141). f. B. chloroglossum Rchb.f. - peças florais (W.S. Mancinelli et al. 1129). g. B. epiphytum Barb.Rodr. - peças florais (A. Seidel 1220). h. B. mentosum Barb.Rodr. - peças florais (E.C. Smidt 656). i-k. B. micranthum Barb.Rodr. - i. vista geral; j. peças florais; k. coluna e labelo em vista lateral (G. Hatschbach 20027). Figure 1 - a. Bulbophyllum meridense Rchb.f. - floral parts (W.S. Mancinelli \& L. Ceolin 1217). b-d. B. peri Schltr. - b. floral parts; c. column in frontal view; d. column and lip in lateral view (W.S. Mancinelli \& M.E. Engels 1143). e. B. tripetalum Lindl. - floral parts (W.S. Mancinelli \& M.E. Engels 1141). f. B. chloroglossum Rchb.f. - floral parts (W.S. Mancinelli et al. 1129). g. B. epiphytum Barb.Rodr. - floral parts (A. Seidel 1220). h. B. mentosum Barb. Rodr.-floral parts (E.C. Smidt 656). i-k. B. micranthum Barb.Rodr.-i. general view; j. floral parts; k. column and lip in lateral view (G. Hatschbach 20027). 
apice acutis; petalis linear-ovalibus, apice cuneatis; labello piloso, trilobato, epichilio orbiculare, apice plica.

Epífita. Rizoma 1-1,8 cm compr. Pseudobulbo $0,9-2,5 \times 0,8-1,8 \mathrm{~cm}$. Folha $2,1-6,3 \times 1-2,4$ $\mathrm{cm}$, elíptica a oblonga, ápice agudo a obtuso. Inflorescência ca. 15 flores; escapo 22 cm compr.; raque ca. 13,9 cm compr., ereta. Sépalas purpúreas com face interna amarela com pontuações purpúreas; sépala dorsal 9-9,5 × 3,5-4 mm, lanceolada, 3-nervada, margem glabra, ápice agudo; sépalas laterais 9-9,5 × 3,5-4 mm, lanceoladas, 3-nervadas, margem glabra, ápice agudo; pétalas $2,5 \times 1,5 \mathrm{~mm}$, linear-ovadas, brancas com listras transversais e margem purpúrea, 1-nervadas, margem glabra, ápice agudo; labelo ca. $6 \times 3,5 \mathrm{~mm}$, lobo mediano orbicular, lobos laterais orbiculares, amarelo com máculas pretas a vermelhas, calo com sulco, margem inteira, pilosa, ápice arredondado, apresentando prega, liso.

Bulbophyllum $\times$ guartelae floresce nos meses de março e abril. É conhecido por apenas um indivíduo encontrado no município de Tibagi (PR), onde se localizam populações simpátricas de $B$. peri e $B$. tripetalum com sobreposição dos períodos de floração. As características desse híbrido são intermediarias entre $B$. peri e $B$. tripetalum, com relação ao distanciamento entre flores na inflorescência, tamanho, forma e coloração das peças florais. Pode ser reconhecido pelo lobo mediano orbicular plano com apenas a região apical apresentando uma prega. Na seção Didactyle as espécies apresentam oferta de néctar (Teixeira et al. 2004), sendo a mobilidade do labelo com auxílio do vento fator essencial à polinização (Borba \& Semir 1998b). Foi constatada nesta seção a autocompatibilidade e a viabilidade de sementes em cruzamentos interespecíficos (Borba et al. 1999), sendo a gradual redução de tamanho das polínias - provavelmente via desidratação uma barreira para a autopolinização e polinização interespecífica (Borba \& Semir 1999). Bulbophyllum $\times$ cipoense Borba \& Semir, único hibrido descrito até o momento e também pertencente a esta seção, apresenta autoincompatibilidade ou esterilidade como mecanismo de isolamento pós-polinização (Borba \& Semir 1998a). Em B. peri e B. tripetalum são desconhecidos os polinizadores ou os recursos para a atração dos mesmos. Em ambos ocorre a mobilidade do labelo em decorrência do vento, porém há diferença perceptível quanto ao tamanho, forma e coloração das peças florais (especialmente o labelo), coluna, cavidade estigmática e polínias. Devido ao fato de ser encontrado apenas um indivíduo com tais feições intermediárias, não pode ser avaliado a fertilidade ou atratividade do mesmo aos polinizadores, sendo necessários maiores estudos sobre a biologia reprodutiva dos parentais e do híbrido em questão.

2. Bulbophyllum sect. Micranthae Barb.Rodr., Gen. et Espec. Orch. Nov. 2: 117. 1882.

Pseudobulbo globoso a ovóide. Folha plana ou cilíndrica, carnosa. Inflorescência delgada ou espessada, flores espiraladas, escapo cilíndrico ou em forma de fita, raque pêndula ou geniculada. Sépalas livres, planas ou naviculares; pétalas planas; labelo inteiro ou trilobado, apêndices basais ausentes, calo ausente ou presente, quilha carnosa abaxial ausente. Coluna com estelídeos ultrapassando ou não a antera; dentes ausentes; pé da coluna inteiro.

\section{Chave de identificação para as espécies de Bulbophyllum sect. Micranthae ocorrentes no sul do Brasil}

1. Escapo floral em forma de fita, labelo inteiro, margem pilosa 2.3. B. mentosum

1'. Escapo floral cilíndrico, labelo trilobado, margem glabra.

2. Folha cilíndrica 2.2. B. epiphytum

2'. Folha plana.

3. Inflorescência com 8 a 44 flores, sépalas brancas, labelo papiloso.

2.4. B. micranthum

3'. Inflorescência com 64 a 80 flores, sépalas brancas com pontuações purpúreas, labelo liso .. 2.1. B. chloroglossum

2.1. Bulbophyllum chloroglossum Rchb.f., Gard. Chron. 1871: 1194. 1871. Fig. 1f

Epífita. Rizoma 4-6 mm compr. Pseudobulbo $18-20 \times 5,5-10 \mathrm{~mm}$, ovóide. Folha $2-4,8 \times 0,7-1,1$ $\mathrm{cm}$, plana, elíptica a oblonga, ápice agudo a obtuso.
Inflorescência delgada, 64-80 flores; escapo 4,2-5,8 cm compr., cilíndrico; raque 14,1-29,5 cm compr., pêndula. Sépalas brancas com pontuações purpúreas; sépala dorsal ca. $4 \times 1 \mathrm{~mm}$, linear, 1-nervada, margem glabra, ápice obtuso, plano; 
sépalas laterais ca. $5 \times 3-3,5 \mathrm{~mm}$, deltóides, 1-nervadas, margem glabra, ápice agudo, plano; pétalas 3-3,5 × $1 \mathrm{~mm}$, elípticas, brancas com nervura e pontuações purpúreas, 1-nervadas, margem glabra, ápice agudo; labelo 4,5-5 × 1,5-2 mm, trilobado, lobo mediano oblongo, lobos laterais dentiformes, verde a amarelo, calo ausente, disco com sulco, margem inteira, glabra, ápice arredondado, liso. Coluna com estelídeos não ultrapassando a antera. Material selecionado: PARANÁ: Sengés, 19.I.1965, fl., L.B. Smith et al. 14852 (FLOR, HB).

Bulbophyllum chloroglossum é endêmica do Brasil (GO, MG, PR, RJ, SP). Floresce no mês de janeiro. Pabst \& Dungs (1975) haviam citado esta espécie para o estado do Rio Grande do Sul, porém nenhum registro em herbário foi encontrado. Encontrada no Paraná em áreas de Cerrado. Esta espécie é semelhante a B. micranthum Barb. Rodr., porém é diferenciada pela sua folha plana, inflorescência com 64 a 80 flores e superfície do labelo lisa.

2.2. Bulbophyllum epiphytum Barb.Rodr., Gen. Spec. Orchid. 1: 40. 1877.

Fig. $1 \mathrm{~g}$

Epífita. Rizoma 1-2 mm compr. Pseudobulbo 11-15 × 7-8 mm, globoso a ovóide. Folha 3,5-4 $\times 0,2-0,3 \mathrm{~cm}$, cilíndrica, linear, ápice agudo. Inflorescência delgada, 25-53 flores; escapo 9,4-17,4 cm compr., cilíndrico; raque 4,2-10,3 cm compr., pêndula. Sépalas brancas; sépala dorsal ca. $4 \times 1-1,5 \mathrm{~mm}$, linear, 1-nervada, margem glabra, ápice agudo, plano; sépalas laterais ca. 4 × 2-2,5 $\mathrm{mm}$, deltóides, 1-nervadas, margem glabra, ápice agudo, plano; pétalas 2,5 × $1 \mathrm{~mm}$, linear-elípticas, brancas, 1-nervadas, margem glabra, ápice agudo; labelo 3-4 × 1-1,5 mm, trilobado, lobo mediano oblongo, lobos laterais dentiformes, amarelo, calo ausente, disco com sulco, margem inteira, glabra, ápice arredondado, liso. Coluna com estelídeos não ultrapassando a antera.

Material selecionado: PARANÁ: Piraí do Sul, fl., $A$. Seidel 1220 (HB).

Material adicional selecionado: MINAS GERAIS: Bom Jardim de Minas, I.1961, fl., E. Saléh 6-A (HB). SÃO PAULO: Mogi Guaçú, 16.X.1981, fl., F. Barros 652 (SP).

Bulbophyllum epiphytum ocorre na Bolívia e no Brasil (GO, MT, MG, PR, SP). Floresce entre outubro e fevereiro. No Paraná foi coletada somente no município de Piraí do Sul, no Cerrado. As flores desta espécie são semelhantes às de $B$. chloroglossum e B. micranthum, porém suas folhas são cilíndricas e a superfície do labelo é lisa.
2.3. Bulbophyllum mentosum Barb.Robr., Gen. Spec. Orchid. 1:42. 1877.

Fig. $1 \mathrm{~h}$

Rupícola. Rizoma 2,5-4 cm compr. Pseudobulbo 3-4,2 × 1,7-2,3 cm, ovóide. Folha 14,3-19,4 × 2,8-3,1 cm, plana, oblonga, ápice obtuso. Inflorescência espessada, 7-9 flores; escapo 9,2-28,9 cm compr., em forma de fita; raque 4,2-5,4 cm compr., geniculada. Sépalas castanhas com listras purpúreas; sépala dorsal 10-13 × 3-4 $\mathrm{mm}$, oblonga, 3-nervada, margem glabra, ápice agudo, navicular; sépalas laterais 10-13 × 5-6 $\mathrm{mm}$, lanceoladas, 3-nervadas, margem glabra, ápice agudo, navicular; pétalas 8-10 × 2-3 $\mathrm{mm}$, lineares, purpúreas, 1-nervadas, margem pilosa, ápice agudo; labelo 3-4 × 3-5 mm, inteiro, largooblongo, purpúreo e verde, calo presente, calo com sulco, margem inteira, pilosa, ápice retuso, liso. Coluna com estelídeos ultrapassando a antera. Material selecionado: SANTACATARINA: Florianópolis, 1951, J.A. Rohr 2133 (FLOR).

Material adicional selecionado: BAHIA: Palmeiras, 2004, fl., E.C. Smidt 656 (HUEFS).

Bulbophyllum mentosum é endêmica do Brasil (BA, GO, MG, RJ, SC). Floresce entre os meses de dezembro e abril. Ocorre em Santa Catarina, na Floresta Ombrófila Densa. As duas exsicatas referentes ao estado de Santa Catarina provém de exemplares estéreis, onde se preservou somente o escapo floral em forma de fita, característica suficiente para a distinção desta espécie. Esta espécie é comumente encontrada na Bahia em áreas de caatinga (Smidt 2007), o que difere de qualquer vegetação do sul do Brasil, tornando necessário maiores estudos para sua confirmação como espécie nativa da região. A espécie diferencia-se pelo escapo floral em forma de fita, labelo inteiro e piloso.

2.4. Bulbophyllum micranthum Barb.Rodr., Gen. Spec. Orchid. 1: 39. $1877 . \quad$ Fig. 1i-k

Epífita. Rizoma 1-5 mm compr. Pseudobulbo $8-11,5 \times 5,5-9 \mathrm{~mm}$, globoso a ovóide. Folha 13,5-47 × 5-9 mm, plana, elíptica a oblonga, ápice obtuso. Inflorescência delgada, 8-44 flores; escapo 25,5-38,5 mm compr., cilíndrico; raque $22-91 \mathrm{~mm}$ compr., pêndula. Sépalas brancas; sépala dorsal 3,5-5 × ca. $1 \mathrm{~mm}$, linear, 1-nervada, margem glabra, ápice agudo, plano; sépalas laterais 4-6 × 2-2,5 mm, deltóides, 1-nervadas, margem glabra, ápice agudo, plano; pétalas 3-4 × ca. $1 \mathrm{~mm}$, elípticas, brancas, 1-nervadas, margem glabra, ápice agudo; labelo 

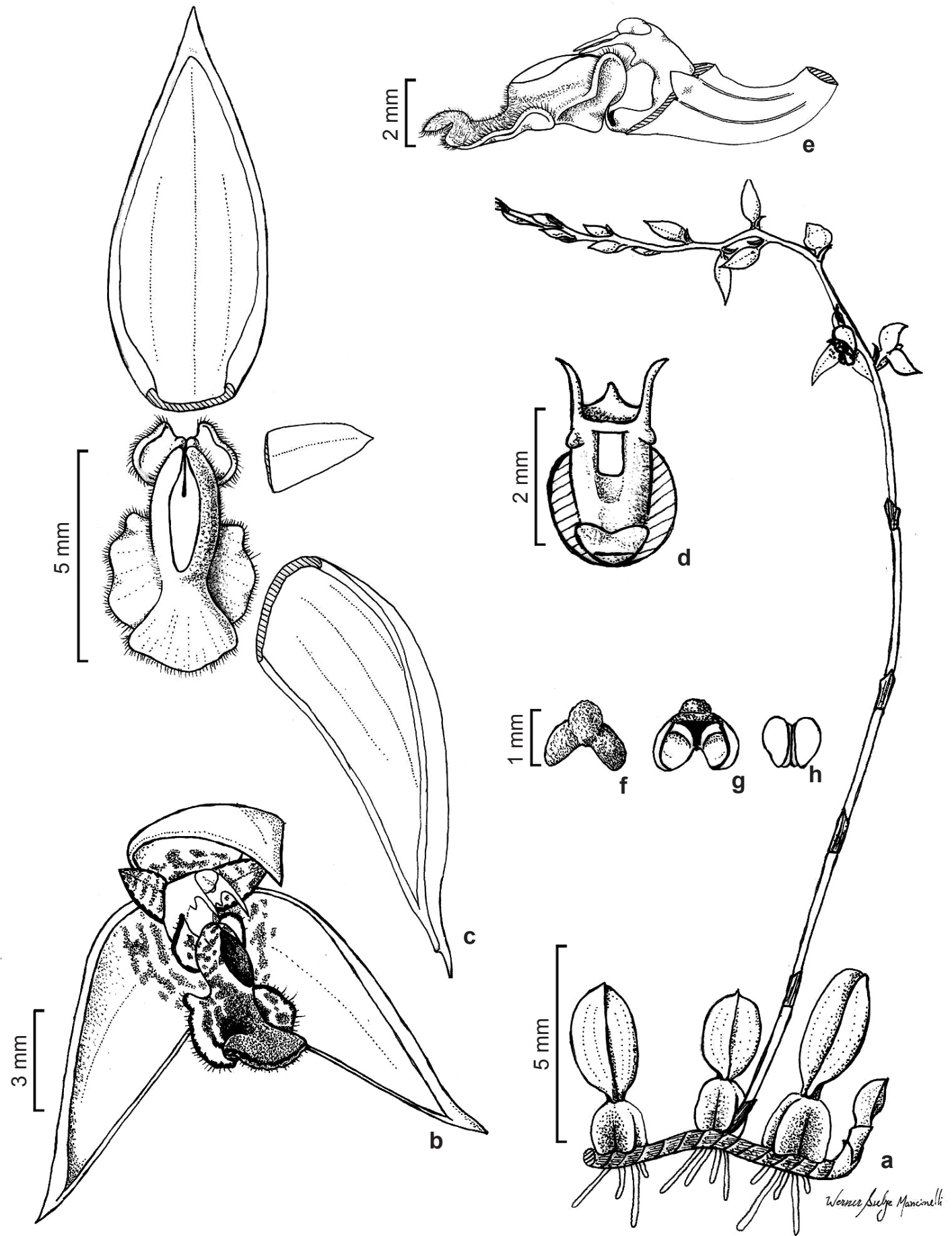

Figura 2 - a-g. Bulbophyllum $\times$ guartelae Mancinelli \& E.C.Smidt - a. vista geral; b. flor; c. peças florais; d. coluna em vista frontal; e. coluna e labelo em vista lateral; f. antera em vista dorsal; g. antera em vista ventral; h. polínias (W.S. Mancinelli \& D.L. Ferreira 1173).

Figure 2 - a-g. Bulbophyllum $\times$ guartelae Mancinelli \& E.C.Smidt - a. general view; b. flower; c. floral parts; d. column in frontal view; e. column and lip in lateral view; f. anther in dorsal view; g. anther in ventral view; h. pollinia (W.S. Mancinelli \& D.L. Ferreira 1173). 
3-4,5 $\times 1-1,5 \mathrm{~mm}$, trilobado, lobo mediano oblongo, lobos laterais dentiformes, amarelo, calo ausente, disco com sulco, margem inteira, glabra, ápice agudo a arredondado, papiloso. Coluna com estelídeos não ultrapassando a antera.

Material selecionado: PARANÁ: Arapoti, 12.X.1968, fl., G. Hatschbach 20027 (HB, HBR, MBM, SP, UPCB).

Bulbophyllum micranthum é endêmica do Brasil (MG, PR, RJ). No Paraná ocorre nos remanescentes de Cerrado. Floresce entre os meses de setembro e novembro. Espécie semelhante a $B$. chloroglossum e $B$. epiphytum, porém distingui-se da primeira pela inflorescência com 8 a 44 flores, e da segunda pela folha plana e de ambas pela superfície do labelo papilosa.

3. Bulbophyllum sect. Napelli Rchb.f., Ann. Bot. 6: 249. 1861.

Pseudobulbo ovóide. Folha plana, coriácea. Inflorescência delgada, flores dísticas, escapo cilíndrico, raque geniculada. Sépalas livres, planas; pétalas planas; labelo inteiro, apêndices basais presentes ou ausentes, calo ausente, quilha carnosa abaxial ausente ou presente. Coluna com estelídeos não ultrapassando a antera; dentes presentes; pé da coluna inteiro.

\section{Chave de identificação para as espécies de Bulbophyllum sect. Napelli ocorrentes no sul do Brasil}

1. Labelo branco a verde-claro, não sulcado, quilha carnosa abaxial ausente.

2. Ápice da pétala agudo, margem do labelo crenada na base .............................. 3.6. B. regnellii

2'. Ápice da pétala arredondada, margem do labelo lisa 3.5. B. napelli

1'. Labelo predominantemente purpúreo, sulcado, quilha carnosa abaxial presente.

3. Sépalas 3-nervadas.

4. Labelo 3-4 mm compr., com apêndices basais

3.3. B. granulosum

4'. Labelo 6-7,5 mm compr., sem apêndices basais 3.1. B. atropurpureum

3'. Sépalas 5-nervadas.

5. Labelo liso, quilha carnosa abaxial estendendo-se até a metade do labelo ....... 3.2. B. glutinosum

5'. Labelo rugoso, quilha carnosa abaxial estendendo-se até o ápice do labelo

3.4. B. malachadenia

3.1. Bulbophyllum atropurpureum Barb.Rodr., Gen. Spec. Orchid. 1: 41. $1877 . \quad$ Fig. 3a Epífita. Rizoma 1-3,2 cm compr. Pseudobulbo $1,4-3,2 \times 0,6-1,1 \mathrm{~cm}$. Folha $6,2-9,5 \times 1,1-1,8 \mathrm{~cm}$, oblonga, ápice agudo a obtuso. Inflorescência 5-9 flores; escapo 9,1-23,2 cm compr.; raque 3,1-8,3 cm compr. Sépalas purpúreas; sépala dorsal 6-8 × 6-8 $\mathrm{mm}$, ovada, 3-nervada, margem glabra, ápice agudo; sépalas laterais 7-8 ×5,5-6 mm, deltóides, 3-nervadas, margem glabra, ápice agudo; pétalas c.a 0,5 × 1-1,5 mm, deltóides, purpúreas, 1-nervadas, margem glabra, ápice obtuso; labelo 6-7,5 × 3-3,5 mm, oblongo a oblanceolado, purpúreo, apêndices basais ausentes, disco com sulco, quilha carnosa abaxial presente, estendendo-se até a metade do labelo, margem inteira, glabra, ápice arredondado, liso.

Material selecionado: PARANÁ: sine loco, XI.1918, fl., P. Dusén (M).

Material adicional selecionado: MINAS GERAIS: Nova Lima, 30.III.1945, fl., L.O. Williams \& V. Assis 6493 (RB). SÃO PAULO: Serra da Bocaína, 16.IV.1951, fl., A.C. Brade 20990 (RB).

Bulbophyllum atropurpureum é endêmica do Brasil (ES, MG, PR, RJ, SP). Floresce entre os meses de março e junho. O único exemplar conhecido para o Paraná não contém informações sobre a localidade. Espécie semelhante a B. glutinosum (Barb.Rodr.) Cogn., B. granulosum Barb.Rodr. e $B$. malachadenia Cogn., distinguindo-se pela flor predominantemente purpúrea, sépalas 3-nervadas e ausência dos apêndices basais no labelo.

\subsection{Bulbophyllum glutinosum (Barb.Rodr.)} Cogn., Fl. bras. 3(5): 597. $1902 . \quad$ Fig. 3b

Epífita. Rizoma 1,1-3,4 cm compr. Pseudobulbo 1,5-3,3 × 0,6-1,9 cm. Folha 3,513,6 $\times 1-2 \mathrm{~cm}$, oblonga, ápice agudo a obtuso. Inflorescência 3-8 flores; escapo 14-28 cm compr.; raque $3,2-7,6 \mathrm{~cm}$ compr. Sépalas verdes com pontuações purpúreas; sépala dorsal 7,5-15 $\times$ 7-9 mm, largo-ovada, 5-nervada, margem glabra, ápice agudo; sépalas laterais 8-13 × 5-8 $\mathrm{mm}$, deltóides, 5-nervadas, margem glabra, ápice agudo; pétalas 1-1,5 × 2-3 mm, rômbicas, verdes com pontuações purpúreas, 1-nervadas, margem glabra, ápice arredondado a obtuso; labelo 5-8 $\times 2-3,5 \mathrm{~mm}$, oblongo a oblanceolado, verde com 

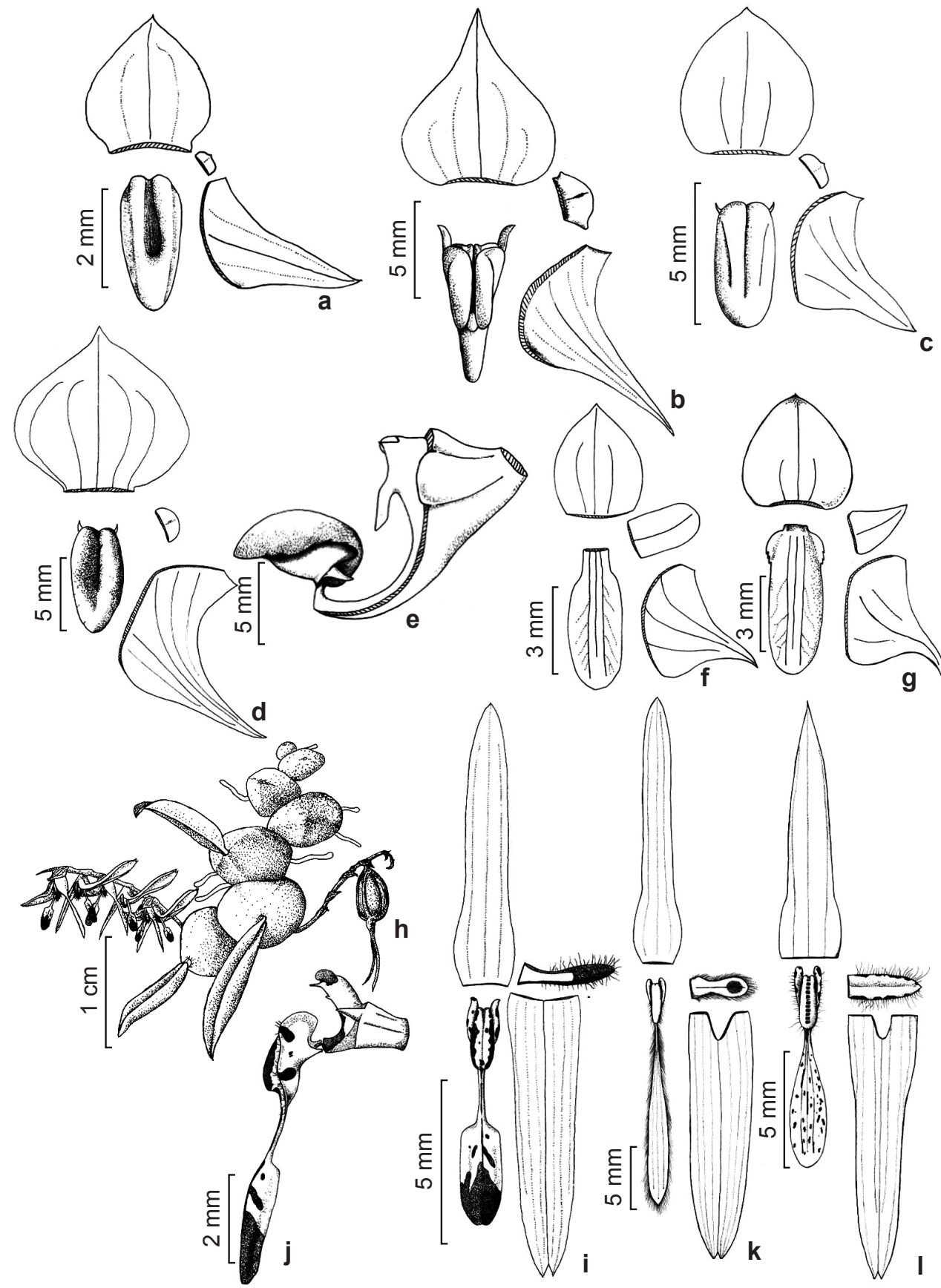

g

Figura 3 - a. Bulbophyllum atropurpureum Barb.Rodr. - peças florais (L.O. Williams \& V. Assis 6489). b. B. glutinosum (Barb. Rodr.) Cogn. - peças florais (W.S. Mancinelli \& J. Hellmann 867). c. B. granulosum Barb.Rodr. - peças florais (W.S. Mancinelli \& I.C. Zattar 1060). d-e. B. malachadenia Cogn. - d. peças florais; e. coluna e labelo em vista lateral (G. Hatschbach 7795). f. B. napelli Lindl. - peças florais (W.S. Mancinelli 1084). g. B. regnellii Rchb.f. - peças florais (W.S. Mancinelli 1058). h-j. B. dusenii Kraenzl. - h. vista geral; i. peças florais; j. coluna e labelo em vista lateral (W.S. Mancinelli 950). k. B. gladiatum Lindl. - peças florais (A. Bresolin 259). 1. B. plumosum (Barb.Rodr.) Cogn. - peças florais (W.S. Mancinelli 861).

Figure 3 - a. Bulbophyllum atropurpureum Barb.Rodr. - floral parts (L.O. Williams \& V. Assis 6489). b. B. glutinosum (Barb.Rodr.) Cogn. - floral parts (W.S. Mancinelli \& J. Hellmann 867). c. B. granulosum Barb.Rodr. - floral parts (W.S. Mancinelli \& I.C. Zattar 1060). d-e. B. malachadenia Cogn. - d. floral parts; e. column and lip in lateral view (G. Hatschbach 7795). f. B. napelli Lindl. - floral parts (W.S. Mancinelli 1084). g. B. regnellii Rchb.f. - floral parts (W.S. Mancinelli 1058). h-j. B. dusenii Kraenzl. - h. general view; i. floral parts; j. column and lip in lateral view (W.S. Mancinelli 950). k. B. gladiatum Lindl. - floral parts (A. Bresolin 259). 1. B. plumosum (Barb.Rodr.) Cogn. - floral parts (W.S. Mancinelli 861). 
pontuações purpúreas, apêndices basais presentes, disco com sulco, quilha carnosa abaxial presente, estendendo-se até a metade do labelo, margem inteira, glabra, ápice arredondado, liso.

Material selecionado: PARANÁ: Guaratuba, 12.V.1997, fl., J. Carneiro 351 (MBM). SANTA CATARINA: Governador Celso Ramos, 11.VIII.1971, fl., R.M. Klein 9647 (FLOR).

Bulbophyllum glutinosum é endêmica do Brasil (ES, MG, PR, RJ, SC, SP). Pabst \& Dungs (1975) citam a espécie para o estado do Rio Grande do Sul, mas após análise do exemplar (PACA 52957) trata-se de B. granulosum. Encontrada em Floresta Ombrófila Densa, comumente na planície litorânea. Floresce entre março e setembro. A espécie é muito semelhante a $B$. atropurpureum, $B$. granulosum e $B$. malachadenia e diferencia-se pela combinação dos seguintes caracteres: sépalas 5-nervadas, labelo liso e quilha carnosa abaxial estendendo-se até a metade do labelo.

3.3. Bulbophyllum granulosum Barb.Rodr., Gen. Spec. Orchid. 1: 41. $1877 . \quad$ Fig. 3c

Epífita. Rizoma $0,7-1,9 \mathrm{~cm}$ compr. Pseudobulbo 1,2-2,2 $\times 0,5-1,8 \mathrm{~cm}$. Folha 3,8-8 $\times$ 0,6-1,2 cm, oblonga, ápice obtuso. Inflorescência 6-10 flores; escapo 11,2-20,9 cm compr.; raque $3,9-7,5 \mathrm{~cm}$ compr. Sépalas verdes na base e purpúreas no ápice; sépala dorsal 5-5,5 × 3,5-5 $\mathrm{mm}$, ovada, 3-nervada, margem glabra, ápice agudo a obtuso; sépalas laterais 5-6 × 3,5-4 mm, deltóides, 3-nervadas, margem glabra, ápice agudo; pétalas $0,5-1 \times 1-2 \mathrm{~mm}$, largo-ovadas, brancas, 1-nervadas, margem glabra, ápice obtuso; labelo 3-4 × 2-2,5 mm, oblongo a oblanceolado, amarelo na porção apical e purpúreo na porção basal, apêndices basais presentes, disco com sulco, quilha carnosa abaxial presente, estendendo-se até a metade do labelo, margem inteira, glabra, ápice arredondado, liso.

Material selecionado: PARANÁ: Piraquara, 18.XI.1951, fl., G. Hatschbach 2659 (MBM, SP). SANTA CATARINA: Campo Alegre, 15.XI.2009, fl., W.S. Mancinelli \& I.C. Zattar 1060 (UPCB). RIO GRANDE DO SUL: Cambará do Sul, 9.IX.1952, fr., $B$. Rambo (HB 2169, PACA 52957).

Bulbophyllum granulosum é endêmica do Brasil (PR, RJ, RS, SC, SP). Encontrada na Floresta Ombrófila Densa e menos comumente em Floresta Ombrófila Mista. Floresce entre os meses de junho e fevereiro. A autofertilização é comum, onde as flores não abrem para a formação de frutos. A espécie é muito semelhante a $B$. atropurpureum,
B. glutinosum e B. malachadenia, porém distinguise pela combinação de dois caracteres: sépalas 3-nervadas e apêndices basais presentes.

3.4. Bulbophyllum malachadenia Cogn., Fl. bras. 3(5): 596. 1902.

Fig. 3d-e

Epífita. Rizoma 0,9-2,2 cm compr. Pseudobulbo 2,4-3,2 × 0,7-1 cm. Folha 6,4-11 $\times 1,1-1,4 \mathrm{~cm}$, oblonga, ápice agudo a obtuso. Inflorescência 1-5 flores; escapo 14,1-20,7 cm compr.; raque 1,9-7,9 cm compr. Sépalas verdes com pontuações purpúreas; sépala dorsal 9-11,5 × 9-12 mm, largo-ovada, 5-nervada, margem glabra, ápice agudo; sépalas laterais 11-13,5 × 6-10 mm, deltóides, 5-nervadas, margem glabra, ápice agudo; pétalas ca. 1,5 × 2-3 mm, largo-deltóides, verdes com pontuações purpúreas, 1-nervadas, margem glabra, ápice arredondado a obtuso; labelo ca. 7 × 3-4 mm, oblongo a oblanceolado, purpúreo, apêndices basais presentes, disco com sulco, quilha carnosa abaxial presente, estendendo-se até o ápice do labelo, margem inteira, glabra, ápice arredondado, rugoso.

Material selecionado: PARANÁ: Adrianópolis, 27.I.2011, f1., W.S. Mancinelli \& A. Soller 1396 (UPCB).

Bulbophyllum malachadenia é endêmica do Brasil (PR, RJ, SP). Floresce entre os meses de agosto e fevereiro. Ocorre no Paraná na Floresta Ombrófila Densa, entre altitudes de 100 a $900 \mathrm{~m}$. Assemelhase muito a $B$. atropurpureum, B. glutinosum e $B$. granulosum, mas diferencia-se por apresentar a seguinte combinação de caracteres: sépalas 5-nervadas e labelo carnoso estendendo-se da base até no ápice.

3.5. Bulbophyllum napelli Lindl., Ann. Mag. Nat. Hist. 10: 185. 1842.

Fig. $3 \mathrm{f}$

Epífita ou rupícola. Rizoma 6,5-60 mm compr. Pseudobulbo 5-18 $\times 2,5-6,5 \mathrm{~mm}$. Folha $17,5-53 \times 3,5-6,5 \mathrm{~mm}$, elíptica a oblonga, ápice agudo a obtuso. Inflorescência 1-3 flores; escapo 21,5-64 mm compr.; raque 3-10 $\mathrm{mm}$ compr. Sépalas brancas a verdes; sépala dorsal 4,5-7 × 4-5 mm, ovada, 3-nervada, margem glabra, ápice agudo; sépalas laterais 6-7 × 4-7 mm, deltóides, 3 -nervadas, margem glabra, ápice agudo; pétalas 3-4 $\times 2-3 \mathrm{~mm}$, oblongas, brancas a verdes com nervura purpúrea, 1-nervadas, margem glabra, ápice arredondado; labelo 5,5-9 × 2-3 mm, oblongo, branco a verde com listras purpúreas, apêndices basais ausentes, disco sem sulco, quilha carnosa abaxial ausente, margem inteira, glabra, ápice arredondado, liso. 
Material selecionado: PARANÁ: São José dos Pinhais, 10.XII.1947, fl., G. Hatschbach 845 (MBM, PACA, SP). SANTA CATARINA: Governador Celso Ramos, 17.XII.1971, fl., A. Bresolin 472 (FLOR, HB, HBR, ICN).

Bulbophyllum napelli é endêmica do Brasil (BA, ES, MG, PR, RJ, SC, SP). Floresce nos meses de novembro a fevereiro. Essa espécie ocorre na Floresta Ombrófila Densa entre altitudes de 300 a 1.200 m. Pabst \& Dungs (1975) citaram esta espécie para o Rio Grande do Sul, porém a análise das exsicatas não confirmou tais dados. Bulbophyllum napelli diferencia-se de $B$. regnellii Rchb.f. por suas pétalas de ápice arredondado e pelo labelo de margem lisa.

3.6. Bulbophyllum regnellii Rchb.f., Linnaea 22 : 835. 1850.

Fig. $3 g$

Epífita. Rizoma 13-49 mm compr. Pseudobulbo 6-19,5 × 3-8 mm. Folha 19-83 × 3-7 mm, elíptica a oblonga, ápice agudo a obtuso. Inflorescência 1-4 flores; escapo 26-81 mm compr.; raque 4-28 mm compr. Sépalas brancas a verdes; sépala dorsal 4,5-6 $\times$ 4-5 mm, ovada a deltóide, 3-nervada, margem glabra, ápice agudo; sépalas laterais 5-7 × 3-5 mm, deltóides, 3-nervadas, margem glabra, ápice agudo; pétalas 1,5-4 × 1-2 mm, ovadas, brancas a verdes com nervura purpúrea, 1-nervadas, margem glabra, ápice agudo; labelo 5,5-8 × 1,5-4 mm, oblongo, branco a verde com listras purpúreas, apêndices basais ausentes, disco sem sulco, quilha abaxial ausente, margem lisa e crenada somente na base, glabra, ápice arredondado, liso.

Material selecionado: PARANÁ: Guarapuava, 22.X.1960, fl., G. Hatschbach 7517 (HB, HBR, MBM). SANTA CATARINA: Abelardo Luz, 26.VIII.1964, fl., R.M. Klein 5543 (FLOR, HB, HBR, ICN, MBM, PACA, RB). RIO GRANDE DO SUL: Vacaria, 28.I.1951, fl., A. Sehnem (PACA 82074).

Bulbophyllum regnellii ocorre na Argentina e no Brasil (MG, PR, RJ, RS, SC, SP). Floresce entre os meses de junho e março. Ocorre nos três estados da região sul, na Floresta Ombrófila Mista. Espécie muito semelhante a $B$. napelli, porém diferenciase por apresentar pétalas de ápice agudo e por apresentar pequenas projeções orbiculares na base do labelo, que ficam dobradas sobre a superfície ventral do labelo e possuem margem crenada.

4. Bulbophyllum sect. Xiphizusa Rchb.f., Bot. Zeit. 10: 919. 1852.

Pseudobulbo globoso a ovóide. Folha plana, coriácea. Inflorescência delgada, flores dísticas, escapo cilíndrico, raque pêndula ou horizontal. Sépala dorsal livre, laterais conatas, naviculares; pétalas planas; labelo trilobado, apêndices basais ausentes, calo presente, quilha carnosa abaxial ausente. Coluna com estelídeos ultrapassando ou não a antera; dentes presentes; pé da coluna inteiro.

\section{Chave de identificação para as espécies de Bulbophyllum sect. Xiphizusa ocorrentes no sul do Brasil}

1. Lobo mediano do labelo piloso, calo sem sulco

1'. Lobo mediano do labelo glabro a esparsamente piloso, calo com sulco.

2. Escapo floral maior que a raque em comprimento, lobo mediano do labelo oblanceolado, calo com sulco com traves transversais 4.3. B. plumosum

2'. Escapo floral menor que a raque em comprimento, lobo mediano do labelo unguiculado, calo com sulco liso 4.1. B. dusenii

4.1. Bulbophyllum dusenii Kraenzl. Kongl. Svenska Vetenskapsakad Handl., n.s., 46(10): 69. 1911. Fig. $3 h-j$ Epífita. Rizoma ca. $2 \mathrm{~mm}$ compr. Pseudobulbo 8-12 × 9-10 mm, globoso a ovóide. Folha 1,8-4 $\times 0,3-0,6 \mathrm{~cm}$, elíptica a oblonga, ápice agudo. Inflorescência 9-10 flores; escapo 3-6 mm compr.; raque $21-52 \mathrm{~mm}$ compr., horizontal. Sépalas verdes com pontuações purpúreas; sépala dorsal $8 \times 2 \mathrm{~mm}$, lanceolada, 3-nervada, margem glabra, ápice agudo; sépalas laterais 7,5-8 × 1,5 mm, linear-lanceoladas, 3-nervadas, margem glabra, ápice agudo; pétalas 2,5$3 \times 0,5 \mathrm{~mm}$, linear-panduriformes, brancas com bordo purpúreo, 1-nervadas, margem pilosa, ápice obtuso; labelo 6-6,5 × $1 \mathrm{~mm}$, lobo mediano unguiculado, lobos laterais orbiculares, branco com pontuações purpúreas, calo com sulco liso, margem inteira, glabra a esparsamente pilosa, ápice arredondado, liso. Coluna com estelídeos não ultrapassando a antera.

Material selecionado: PARANÁ: Ponta Grossa, 28.VII.2009, fl., W.S. Mancinelli 950 (UPCB).

Bulbophyllum dusenii é endêmica do Brasil (MG, PR). Floresce entre os meses de julho a setembro. No Paraná ocorre nos municípios localizados nos Campos Gerais, onde ocorrem manchas de Cerrado e Floresta Ombrófila Mista, sendo comumente 
encontrada junto com B. plumosum (Barb.Rodr.) Cogn. Vegetativamente é muito semelhante a $B$. gladiatum Lindl. e B. plumosum, porém difere pela sua inflorescência com escapo muito curto em relação à raque e pelo lobo mediano do labelo unguiculado.

\subsection{Bulbophyllum gladiatum Lindl., Ann. Mag.} Nat. Hist. 10: 185. 1842.

Fig. 3k

Epífita. Rizoma 0,2-0,4 cm compr. Pseudobulbo 1,1-1,9 × 0,5-1,0 cm, ovóide. Folha 3,55-4,8 × 0,6-1 cm, elíptica a oblonga, ápice agudo. Inflorescência 6-13 flores; escapo 5,9-12,8 cm compr.; raque 2,4-5,3 cm compr., horizontal. Sépalas verdes; sépala dorsal 13-20,5 ×2-3,5 mm, linear-lanceolada, 3-nervada, margem glabra, ápice agudo; sépalas laterais 13-20 × 1,5-2 mm, linear-lanceoladas, 3-nervadas, margem glabra, ápice agudo; pétalas 3,5-4,5 × 1-1,5 mm, linear-panduriformes, verdes com mácula circular purpúrea, 1-nervadas, margem pilosa, ápice obtuso; labelo 11-17 × 1-1,5 mm, lobo mediado oblanceolado, lobos laterais orbiculares, verde, calo sem sulco, margem inteira, pilosa, ápice obtuso, liso. Coluna com estelídeos ultrapassando a antera.

Material selecionado: PARANÁ: Porto Amazonas, 12.VI.1916, fl., R. Lange \& P. Dusén 3531 (HB, MBM). SANTA CATARINA: Governador Celso Ramos, 26.VI.1971, fl., A. Bresolin 259 (FLOR).

Bulbophyllum gladiatum ocorre no Paraguai e no Brasil (BA, DF, ES, MG, PR, RJ, SC, SP). Floresce entre junho e julho. Distribui-se na Região Sul por áreas paranaenses de Cerrado e dos Campos Gerais, conhecida também para Governador Celso Ramos (SC), na Floresta Ombrófila Densa. Espécie muito semelhante a $B$. plumosum, diferindo-se pela pilosidade densa existente no labelo e pelo calo de superfície lisa.

\subsection{Bulbophyllum plumosum (Barb.Rodr.) Cogn.,} Fl. bras. 3(5): 614. 1902.

Fig. 31

Epífita ou rupícola. Rizoma $2-4 \mathrm{~mm}$ comr. Pseudobulbo 5-9 × 6,5-11 mm, globoso a ovóide. Folha 2,6-4,9 × 0,6-1 cm, elíptica a oblonga, ápice agudo. Inflorescência 3-10 flores; escapo 3,35-4,6 cm compr.; raque 1,8-5,2 cm compr., pendula. Sépalas verdes; sépala dorsal 10-15 × 1,5-2 mm, linear-lanceolada, 3-nervada, margem glabra ou pilosa, ápice agudo; sépalas laterais $11-15 \times 1,5-2,5$ $\mathrm{mm}$, linear-lanceoladas, 3-nervadas, margem glabra ou pilosa, ápice agudo; pétalas 2,5-4,5 × 1-1,5 mm, lanceoladas, brancas com pontuações purpúreas, 1-nervadas, margem pilosa, ápice agudo; labelo 9,5-12,5 × 1-2 mm, lobo mediano oblanceolado, lobos laterais orbiculares, branco com pontuações e nervuras purpúreas, calo com sulco com traves transversais, margem inteira, glabra ou esparsamente pilosa, ápice arredondado, liso. Coluna com estelídeos ultrapassando a antera.

Material selecionado: PARANÁ: Tibagi, 31.III.1963, fl., G. Hatschbach 59100 (MBM).

Bulbophyllum plumosum é endêmica do Brasil (BA, ES, GO, MG, PR, SP). Floresce entre os meses de janeiro e abril. Distribui-se no Paraná ao longo dos Campos Gerais no Cerrado. Espécie semelhante a B. dusenii e B. gladiatum, diferenciando-se de ambas pela presença de traves transversais no sulco do calo. Também difere de $B$. dusenii pelo escapo floral maior que a raque e pelo lobo mediano do labelo oblanceolado e de B. gladiatum pelo lobo mediano glabro ou esparsamente piloso.

\section{Agradecimentos}

Ao IAP (No 153/09) e IBAMA (N 19749-1 e $N^{o}$ 20433-1), as autorizações de pesquisa e coleta nas unidades de conservação. Ao CNPq (130250/2009-0) e CAPES (PNADB 17/2009) o financiamento desta pesquisa.

\section{Referências}

Barros, F.; Vinhos, F.; Rodrigues, V.T.; Barberena, F.F.V.A. \& Fraga, C.N. 2010. Orchidaceae. In: Forza, R.C. et al. (eds.). Lista de espécies da flora do Brasil. Jardim Botânico de Rio de Janeiro. Disponível em <http://floradobrasil.jbrj.gov. br/2010/FB000179>. Acesso em 25 Abr 2011.

Borba, E.L. \& Semir, J. 1998a. Bulbophyllum $\times$ cipoense (Orchidaceae), a new natural hybrid from the Brazilian "Campos Rupestres": description and biology. Lindleyana 13: 113-120.

Borba, E.L. \& Semir, J. 1998b. Wind-assisted fly pollination in three Bulbophyllum (Orchidaceae) species occurring in the Brazilian "Campos Rupestres". Lindleyana 13: 203-218.

Borba, E.L. \& Semir, J. 1999. Temporal variation in pollinarium size after its removal in species of Bulbophyllum: a different mechanism preventing selfpollination in Orchidaceae. Plant Systematics and Evolution 217: 197-204.

Borba, E.L.; Shepherd, G.J. \& Semir, J. 1999. Reproductive systems and crossing potential in three species of Bulbophyllum (Orchidaceae) occurring in Brazilian "Campo Rupestre" vegetation. Plant Systematics and Evolution 217: 205-214.

Chase, M.W.; Cameron, K.M.; Barrett, R.L. \& Freudenstein, J.V. 2003. DNA data and Orchidaceae systematics: a new phylogenetic classification. In: Dixon, K.W.; Kell, S.P.; Barrett, R.L. \& Cribb, P.J. (eds.). Orchid conservation. Natural History Publications, Kota Kinabalu, Sabah. Pp. 69-89. 
Dressler, R. 2005. How many orchid species? Selbyana 26: $155-158$.

Fidalgo, O. \& Bononi, V.L.R. 1989. Técnicas de coleta, preservação e herborização de material botânico. Instituto de Botânica, São Paulo. 62p.

Fortes, A.B. 1979. Compêndio de geografia geral do Rio Grande do Sul. $6^{\mathrm{a}}$ ed. Sulina, Porto Alegre. 101p.

Hagedorn, G. 2010. DeltaAccess a SQL interface to DELTA, the description language for taxonomy, implemented in Microsoft Access 97, 2000, and 2002 (XP). Disponível em <http://www. diversityworkbench.net/OldModels/Descriptions/ index.html>. Acesso em 17 Ago 2010.

Instituto Brasileiro de Geografia e Estatística - IBGE. 2004. Mapa de vegetação do Brasil. Disponível em <http://www.ibge.gov.br/home/presidencia/ noticias/21052004biomas.shtm>. Acesso em 14 Fev 2011.

Pabst, G.F.J. \& Dungs, F. 1975. Orchidaceae Brasiliensis. Vol. 1. Kurt Schmersow, Hildeshein. 408p.

Pridgeon, A.M.; Cribb, P. \& Chase, M.W. 2005. Genera orchidacearum: Epidendroideae. Vol. 4, Part. 1. Oxford University Press, New York. 672p.
Smidt, E.C. 2007. Filogenia e revisão taxonômica de Bulbophyllum Thouars (Orchidaceae) ocorrentes no neotrópico. Tese de Doutorado. Universidade Estadual de Feira de Santana, Feira de Santana. 345p.

Smidt, E.C.; Silva-Pereira, V.; Borba, E.L. \& van den Berg, C. 2007. Richness, distribution and important areas to preserve Bulbophyllum in the neotropics. Lankesteriana 7: 107-113.

Stevens, P.F. 2001. Angiosperm Phylogeny Website. Version 9, June 2008. Disponível em $<$ http://www. mobot.org/MOBOT/research/aPweb/>. Acesso em 13 Mar 2011.

Teixeira, S.P.; Borba, E.L. \& Semir, J. 2004. Lip anatomy and its implications for the pollination mechanisms of Bulbophyllum species (Orchidaceae). Annals of Botany 93: 499-505.

Thiers, B. 2011. Index Herbariorum: a global directory of public herbaria and associated staff. Disponível em $<$ http://sweetgum.nybg.org/ih/>. Acesso em 10 Abr 2011.

Vermeulen, J.J. 1987. A taxonomic revision of the continental African Bulbophyllinae. Brill Archive, Leiden. 300p.

\section{Lista de exsicatas do Paraná:}

Bonnet, A. 71293 (4.1), 71294 (4.3), 111072 (3.6). Brotto, M.L. 247 (3.6). Carneiro, J. 351 (3.2), 397 (1.3), 1442 (1.2). Caxambu, M.G. 1431 (1.2). Dombrowski, L.T. 4475 (3.5), 11809 (3.6). Dusén, P. s.n. (3.1), 10110 (4.1), 11721 (1.3), 16477 (2.1). Engels, M.E. 48 (3.6), 114 (3.6), 160 (4.3), 161 (4.1). Ferrarezi, E. 27 (1.3). Hatschbach, G. 845 (3.5), 1816 (3.4), 2113 (3.5), 2329 (3.2), 2659 (3.3), 2979 (4.3), 3145 (4.2), 3229 (3.2), 3267 (1.3), 3306 (2.4), 3575 (1.3), 6702 (3.5), 7517 (3.6), 7795 (3.4). 12324 (2.1), 12418 (4.3), 14009 (1.3), 14206 (4.3), 14390 (3.2), 15022 (3.6), 15559 (3.5), 16519 (3.2), 19567 (3.2), 20027 (2.4), 20732 (3.5), 22697 (3.6), 34516 (3.6), 44416 (3.6), 45497 (3.6), 59100 (4.3). Hoehne, F.C. s.n. (2.4). Imaguire, N. 5330 (3.3). Kersten, R.A. 679 (3.3), 753 (3.5), 935 (3.6), 983 (3.3), $1252(3.3), 1374(3.5)$. Kinupp, V. 252 (1.3). Lange, R. 3531 (4.2). Leinig, M.G. 22 (4.3), 67 (3.5), 114 (1.3), 115 (3.4), 253 (3.2), 271 (3.5), 293 (3.3), 335 (3.2), 344 (3.6). Lemos, J.V. 68 (3.2). Lindman, J.C. 4080 (3.5). Mancinelli, W.S. 861 (4.3), 865 (1.3), 950 (4.1), 966 (4.1), 996 (3.3), 1058 (3.6), $1064 \mathrm{c}$ (3.5), 1085 (3.5), 1120 (4.3), 1121 (1.3), 1129 (2.1), 1137 (1.4), 1141 (1.3), 1142 (1.3), 1143 (1.2), 1144 (4.3), 1164 (1.2), $1172(2.4)$, 1312 (2.4), 1396 (3.4). Pabst, G. s.n. (3.3). Petean, M.P. 11 (3.5), 129 (3.3). Seidel, A. s.n. (1.3), 876 (3.5), 942 (2.4), 945 (1.2), 1220 (2.2). Smith, L.B. 14752 (2.1), 14852 (2.1), 15649 (3.6). Tessmann, G. s.n. (1.2), s.n. (1.2).

\section{Lista de exsicatas de Santa Catarina:}

Bresolin, A. 259 (4.2), 264 (1.1), 344 (3.2), 454 (3.5), 472 (3.5), 663 (3.5). Buzatto, C.R. 346 (3.6). Cadorin, T.J. 265 (3.3). Carneiro, J. 373 (1.1). Cordeiro, J. 1684 (3.3). Gasper, A.L. 781 (3.6), 2196 (3.2). Klein, R.M. 1594 (3.2), 4514 (3.6), 5543 (3.6), 9647 (3.2), 9654 (3.2), 10486 (3.5). Mancinelli, W.S. 659 (3.3), 845 (3.3), 846 (3.5), 867 (3.2), 893 (3.2), 899 (3.2), 1012 (3.3), 1059 (3.3), 1060 (3.3), 1084 (3.5), 1090 (3.5), 1110 (3.3), 1217 (1.1), 1367 (3.5). Mattos, J. 11339 (3.6). Meyer, F.S. 891 (3.3). Reitz, R. 1850 (3.2), 3249 (3.2), 3554 (3.2), 3573 (1.1), 3612 (3.2), 4256 (3.5), 5952 (3.5), 10334 (3.3), 10426 (3.5), 10440 (3.5), 12568 (3.3), 17025 (3.2). Rohr, J.A. s.n. (3.2), 2059 (3.5), 2128 (1.1), 2133 (2.3), 2139 (3.2), 2296 (3.2) 2306 (3.5). Schmitt, J.L. 147 (3.3), 960 (3.5). Schwacke, A. 6946 (3.2). Seidel, A. s.n. (2.3), s.n. (3.2), 867 (3.2). Silva, J.S. 11 (1.1). Smith, L.B. 13042 (3.6), 13530 (3.6).

Lista de exsicatas do Rio Grande do Sul:

Arzivenco, L. 234 (3.6). Birck, S.A. 5 (3.3). Bustulin, C.H. 16 (3.6), 67 (3.6). Buzatto, C.R. s.n. (3.6), 488 (3.6). Dutra, J. s.n. (3.6), 966 (3.6). Fertsch, D. s.n. (3.6). Kleebank, K. 14 (3.6). Pabst, G. 6314 (3.6). Rambo, B. s.n. (3.3). Richter, E. s.n. (3.6). Sehnem, A. s.n. (3.6). Sturmhoefel, R. 1 (3.6). Waechter, J.L. 386 (3.6), 1859 (3.6), 1906 (3.6). Wasum, R. 613 (3.6).

Lista de exsicatas adicionais:

Barros, F. 652 (2.2). Brade, A.C. 20990 (3.1). Cruz, J.F. 42 (1.2). Saléh, E. 6-A (2.2). Smidt, E.C. 656 (2.3). Williams, L.O. 6493 (3.1). 
